\title{
Article \\ Vibration Damping Behavior of Composite Laminates Interleaved with PZT- and SMA-Particle-Dispersed Resin Mixture Films
}

\author{
Jae-Min Jung ${ }^{1}$, Da-Som Lee ${ }^{1}$, Sung-Ha Kim ${ }^{1}$, Sung-Nam Moon ${ }^{1}$, Woo-Il Lee ${ }^{1}$ and Seung-Mo Kim ${ }^{2, *}$ \\ 1 Department of Mechanical and Aerospace Engineering, Seoul National University, Seoul 08826, Korea; \\ jmjung@snu.ac.kr (J.-M.J.); dslee07@snu.ac.kr (D.-S.L.); katcha06@gmail.com (S.-H.K.); \\ masterl1@snu.ac.kr (S.-N.M.); wilee@snu.ac.kr (W.-I.L.) \\ 2 School of Mechanical Engineering, Korea University of Technology and Education, 1600 Choong Jeol Ro, \\ Cheonan 31253, Korea \\ * Correspondence: smkim@koreatech.ac.kr; Tel.: +82-415-601-159
}

check for updates

Citation: Jung, J.-M.; Lee, D.-S.; Kim, S.-H.; Moon, S.-N.; Lee, W.-I.; Kim, S.-M. Vibration Damping Behavior of Composite Laminates Interleaved with PZT- and SMA-Particle-Dispersed Resin Mixture Films. Appl. Sci. 2021, 11,7155. https://doi.org/10.3390/ app11157155

Academic Editor:

Giangiacomo Minak

Received: 30 June 2021

Accepted: 27 July 2021

Published: 3 August 2021

Publisher's Note: MDPI stays neutral with regard to jurisdictional claims in published maps and institutional affiliations.

Copyright: (c) 2021 by the authors. Licensee MDPI, Basel, Switzerland. This article is an open access article distributed under the terms and conditions of the Creative Commons Attribution (CC BY) license (https:/ / creativecommons.org/licenses/by/ $4.0 /)$.

\begin{abstract}
In this study, functional particles such as piezoelectric (PZT) ceramic and shape memory alloy (SMA) particles have been incorporated in composite laminates to accelerate the loss of vibration energy. PZT ceramic particles and SMA particles are mixed with epoxy resin and rolled into a film shape before they are interleaved between prepreg plies for better distribution of the particles. Loss factor $(\tan \delta)$ was measured with various particle loadings to verify the effectiveness of interleaving in the vibration damping of laminate specimens. It was observed that there existed an optimal content for maximizing the damping ability avoiding an aggregation of the particles. In addition, when PZT and SMA particles are applied simultaneously, PZT could enhance the vibration damping capability of SMA because PZT particles could generate thermal energy, and it would accelerate the phase change of the SMA particles. In this research, the effective way for enhancing the particle dispersion was suggested, and the particle loading could be controlled by finding an optimal content. Flexural moduli of the specimens were also measured, and they exhibited no change as the content of the particles increases. Therefore, dispersed particles used in this study increased the vibration damping capacity without reducing the mechanical properties.
\end{abstract}

Keywords: lead zirconate titanate (PZT); shape memory alloy; resin film; polymer matrix composites (PMCs); vibration; loss factor; particle dispersion

\section{Introduction}

Carbon-fiber-reinforced plastic (CFRP) is used in various applications owing to its strength, heat resistance, and corrosion resistance, in addition to its weight advantage over other materials [1-5]. A trend in aerospace applications is to increase the proportion of composite structural parts for aircraft weight reduction and corrosion resistance. In leisure and sporting goods industries, it is widely used in the production of golf shafts, tennis racquets, skis, and snowboards owing to the above advantages. However, despite these advantages, CFRP may not be suited for some structures exposed to large amplitude vibration, owing to its low damping capacity [5]. Recently, various studies have been performed to improve the vibration damping ability of CFRP and studies on functional composite materials that can absorb vibration energy have been drawing more attention.

Recently, particles with nano and micro dimensions have been used as reinforcing materials to enhance the reinforcing effect; they have been added to the polymer matrix for composites to provide better performance. Multifunctional materials containing piezoelectric material such as lead zirconate titanate (PZT) and shape memory alloy (SMA) could increase the damping capacity by converting the vibration energy into heat energy. These materials, referred to as active materials, can convert a non-mechanical input into a mechanical output, or vice versa. The mechanical response of these materials to a 
non-mechanical input is several orders of magnitude larger than the thermal expansion. Piezoelectric material converts mechanical energy into electrical energy, and vice versa [6]. Electrical energy is generated by deformation of piezoelectric ceramic particles during vibration of the composite material, which can lead to current flow if a proper resistance circuit is present [7]. As Joule heat emerges from the generated current as it passes through the resistor, the vibration energy is converted into thermal energy, which increases the vibration damping ability of the material [8].

Tanimoto [9] demonstrated that the carbon-fiber-reinforced composite material itself can function as a proper resistor. Accordingly, the vibration damping mechanism of the piezoelectric ceramics can be applied to enhance the vibration damping. He applied a trial and error method to find the optimal content of piezoelectric ceramic particles. The vibration damping capability of composites increases with the introduction of piezoelectric ceramic particles owing to the electrical connections of the piezoelectric ceramic particles and carbon fibers, acting as resistors. Uchino [10] enhanced the vibration damping ability of composite materials with piezoelectric ceramic particles, used as functional particles accelerating the loss of the vibration energy. Yazdani et al. investigated damping behavior of highly loaded PZT/Polyurethane particulate composite [11]. They fabricated thermoplastic polyurethane elastomer (TPU) composites containing up to 70vol\% PZT particles for increasing damping of composites. SMA is a type of hyperelastic material, which could restore its shape when a particular temperature is reached. When the shape of the material is deformed, its phase and crystal structure change, leading to a conversion of the mechanical energy into thermal energy [12-16]. Studies have been performed to enhance vibration damping of composites utilizing SMA particles $[17,18]$. Piedboeuf and Gauvin investigated the damping behavior of SMA for various frequency and temperature conditions [19]. Juan et al. demonstrated that nanoscale SMA particles are effective for ultra-high mechanical damping [20].

Kim et al. reported that with a dispersion of PZT ceramic particles on the prepreg in a single layer, the vibration damping ability was improved. Because the contact area between PZT and carbon fiber increases, electrical heat losses results in more efficiency [8]. However, in their study, particles were applied directly on the carbon fiber prepreg surface resulting in poor control of dispersion and particle loading. If the particles are not well dispersed, they may act as defects and, thus, the dispersion of particles is a very important parameter in the overall performance of the finished structure. Quiroga et al. improved damping of composite structures by using piezoelectric filler-dispersed films [21]. They made films dispersed piezoelectric and conductive particles in PA or PEKK for enhancing damping of the composite. In their study, the effect of particle dispersion on damping was not analyzed. In this investigation, we established a process to fabricate thin resin mixture films containing PZT and SMA particles within the composites with increased dispersion. By dispersing the particles evenly inside the mixture film and applying them to the carbon fiber reinforced composite material as interleaves, the vibration damping ability of the composite specimen increased.

In the research so far, there have been many studies to improve the vibration damping of composite materials by using PZT particles or SMA particles alone. Of course, there have also been attempts to apply PZT and SMA to composite materials at the same time. Dong et al. fabricated the thin SMA film deposited on PZT substrate composite by sputtering for enhancing damping property [22]. However, devices fabricated in this way are very expensive and difficult to apply to large-area composite materials. In this study, PZT and SMA particles were applied separately to composite laminates to evaluate the vibration damping efficiency. In order to observe the effect of particle mixing, both PZT and SMA particles were mixed and applied to composite laminates to evaluate the effect. Particles are dispersed in large area films, so it is easy to apply to a large area and can be manufactured relatively inexpensively. The loss factor $(\tan \delta)$ was used as a parameter to indicate the vibration damping capability, measured using a dynamic mechanical analyzer (DMA). The change in vibration damping as a function of the particles loading was observed. In 
addition, flexural moduli of the interleaved specimens were evaluated to investigate the effect of the interleaved layers on the mechanical performance.

The structure of the paper is as follows: in Section 2, materials and manufacturing methods for making specimens are introduced, and experiment methods to measure the physical properties of specimens are introduced. Section 3, the loss factor according to the frequency of each specimen is examined, and the results are compared. The dispersion degree of the film in which the PZT particles were dispersed was confirmed through the EPMA results, and the loss factor and mechanical properties of the specimens in which the PZT particles and the SMA particles were simultaneously dispersed were confirmed through the experiments. Next, a discussion of the results obtained is provided. Section 4 contains the final conclusions that summarize the most important achievements of the article.

\section{Experimental Methods}

\subsection{Materials}

PZT particles were prepared by crushing a pre-poled PZT ceramic film in a ball mill. The PZT film used in this study (PIC-151, PI Ceramic, Lederhose, Germany) has a density of $7.8 \mathrm{~g} / \mathrm{cm}^{3}$, piezoelectric coefficient $\left(d_{33}\right)$ of $500 \mathrm{pC} / \mathrm{N}$, and Curie temperature of $250{ }^{\circ} \mathrm{C}$. For SMA particles, Nickel titanium (NiTi) powder (Zhengzhou Dongyao Nano Materials, Zhengzhou, China) was used. The PZT and SMA particles were sieved using a $20 \mu \mathrm{m}$ metal sieve. The average diameter of particles thus obtained was approximately $10 \mu \mathrm{m}$. The resin used for the resin film was epoxy resin (YD-128, Kukdo Chemical, Seoul, Korea). Unidirectional carbon/epoxy prepreg USN-150B (SK Chemical, Seoul, Korea) was used to construct composite laminate specimens.

\subsection{Preparation of Specimens}

\subsubsection{Particle-Dispersed Resin Mixture Film}

The resin mixture films laden with PZT and SMA particles were fabricated using custom-made film-casting equipment. First, the particles were added to the epoxy resin. The particles were then evenly dispersed in the resin using a three-roll-mill machine (EXAKT 80E, Oklahoma City, OK, USA). The resin and particle mixture thus obtained was placed into a vacuum oven to dry volatiles in the resin. To fabricate the resin film, the mixture was poured into the resin reservoir of the film casting equipment. A Polyethylene Terephthalate (PET) film, which has been surface-treated so that it can be easily released, passed through the reservoir and subsequently through the rollers. The mixture coated PET film passes through a blade controlling the thickness of the mixture film. In this case, the specimen with a thickness of $20 \mu \mathrm{m}$ was very well casted on the PET film. Specimens in which particles were directly dispersed were also prepared for comparison with filmdispersed particles. In this case, "directly" means dispersed by hand. On the other hand, the particle-dispersed resin mixture film was casted isotropically on PET film and directly transcribed over the unidirectional prepreg. In addition, as the average size of the used particles is $10 \mu \mathrm{m}$, a better dispersion of the particles may be expected with $20 \mu \mathrm{m}$ thick film. The viscosity of the epoxy resin used in film production is $12,000 \mathrm{cps}$ and the density is $1.16 \mathrm{~g} / \mathrm{cm}^{3}$.

\subsubsection{Preparation of Composite Laminate}

In order to manufacture interleaved composite laminate specimens, four plies of unidirectional prepreg $\left(0^{\circ}\right.$ direction) with mixture films interleaved between plies were laid up as shown in Figure 1. The amount of dispersed PZT and SMA particles in the mixture films was varied from $0 \mathrm{~g} / \mathrm{m}^{2}$ to $25 \mathrm{~g} / \mathrm{m}^{2}$ with an increment of $5 \mathrm{~g} / \mathrm{m}^{2}$. For each particle loading, 15 specimens were manufactured. The layups thus prepared were brought into a hot-press and a pressure of $220 \mathrm{kPa}$ was applied. The laminates were cured at $130{ }^{\circ} \mathrm{C}$ for $2 \mathrm{~h}$. The cured laminates were cooled and cut to make DMA test specimens according to the ASTM 5023 standard $(65 \mathrm{~mm} \times 13 \mathrm{~mm} \times 0.8 \mathrm{~mm})$ [23]. 


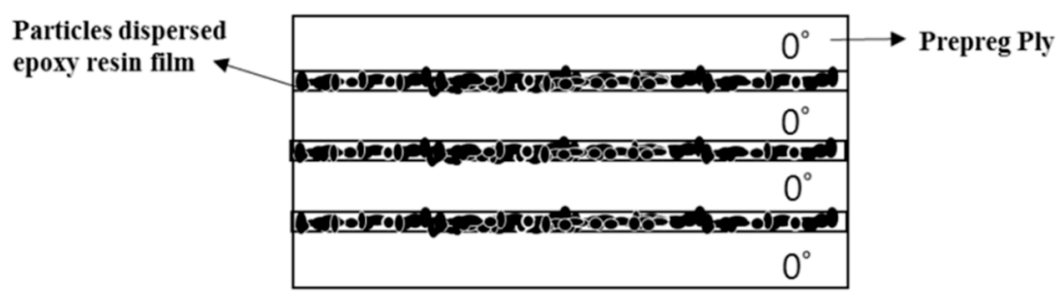

Figure 1. Illustration of the cross-section of the CFRP specimen interleaved with the particle-dispersed mixture film.

\subsection{Measurements}

The dispersion of the particles in the mixture film was observed and evaluated using a SEM (HITACHI S-4800) and an electron probe microanalyzer (EPMA) (JXA-8530F, JEOL Ltd., Seoul, Korea). The vibration damping behavior of the composite specimen was measured using a dynamic mechanical analyzer (Q800 DMA, TA Instruments, New Castle, DE, USA). The tests were performed using 25 specimens per each particle loading. The change in the vibration damping capacity of the specimen was measured with the threepoint bending mode with the frequency sweep range of 5-200 Hz [8]. The damping capability of the material was represented by the loss factor $(\tan \delta)$ which is defined as

$$
\tan \delta=\frac{\text { Loss Modulus }}{\text { Storage Modulus }}
$$

The flexural modulus of the specimen was also measured using a universal testing machine (LR 50K, LLOYD Instruments, Largo, FL, USA). The tests were performed according to ASTM D790 [24]. The size of the prepared specimen is: $50.8 \mathrm{~mm} \times 12.7 \mathrm{~mm} \times 0.8 \mathrm{~mm}$. The span length is $25.4 \mathrm{~mm}(1 \mathrm{in}$.) and test speed is $2 \mathrm{~mm} / \mathrm{min}$. The test was conducted until the fracture of the specimen occurred, and the flexural modulus was derived from the measured data (Figure 2).

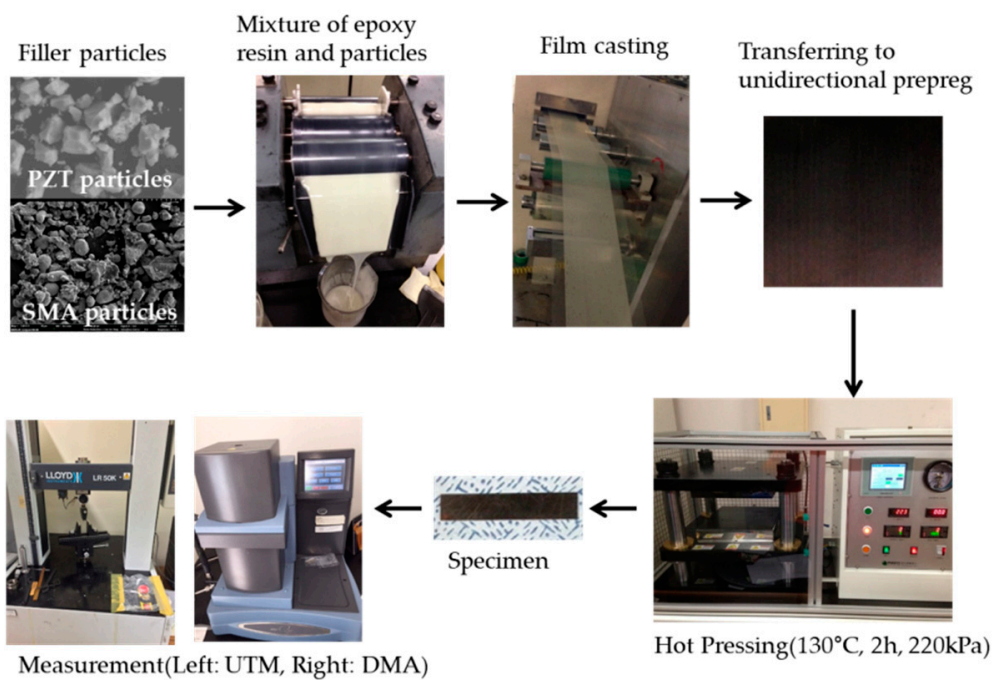

Figure 2. The Specimen preparation and experiment scheme with photos.

\section{Results and Discussion}

Figure 3 shows SEM images of the particle-dispersed epoxy film. The amount of dispersed PZT and SMA particles in the specimens were $20 \mathrm{~g} / \mathrm{m}^{2}$. For the specimen in which both PZT and SMA particles were mixed together, each particle contains $10 \mathrm{~g} / \mathrm{m}^{2}$ to make the total amount of particles in the specimen also $20 \mathrm{~g} / \mathrm{m}^{2}$. As can be seen, both PZT and SMA particles are uniformly distributed in the films. As the SMA particles have a smaller diameter than the PZT particles, the number of particles per unit area is larger for the SMA sample. However, as the densities of the two types of particles are similar, their 
masses per unit area are almost identical. The film specimen with a thickness of $20 \mu \mathrm{m}$ was made with almost no void. It is noted that the films were casted on the substrate film by passing between two counter-rotating rollers with a gap of $20 \mu \mathrm{m}$. Therefore, better dispersion of the particles may be expected with thinner films with the thickness close to the particle diameter. Considering the voids and dispersion of the particles, the best performance was expected for the film with a thickness of $20 \mu \mathrm{m}$ and all subsequent experiments were performed using $20 \mu \mathrm{m}$ thickness mixture films.

(a)

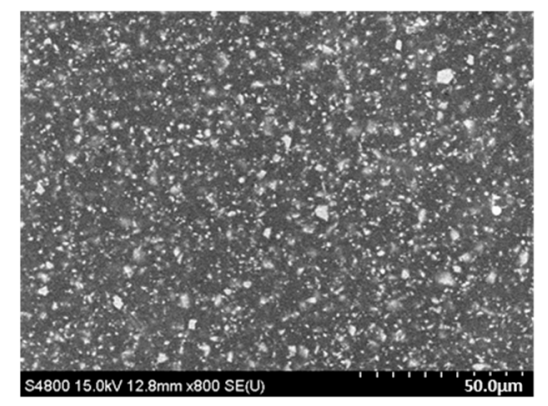

(b)

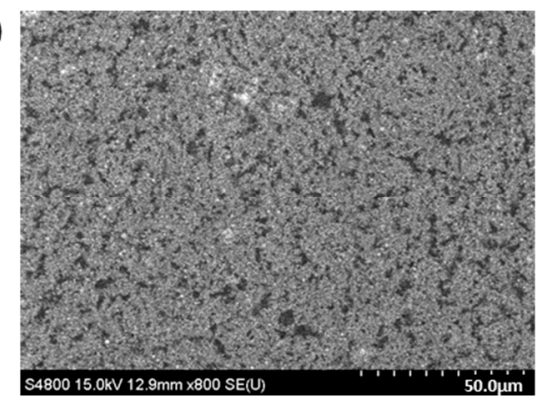

(c)

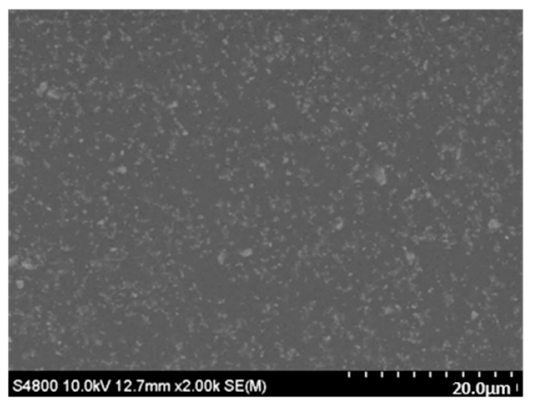

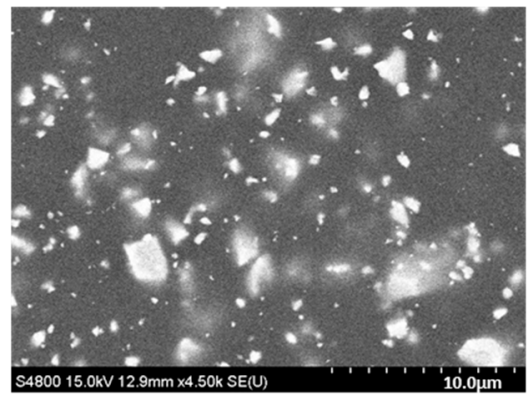
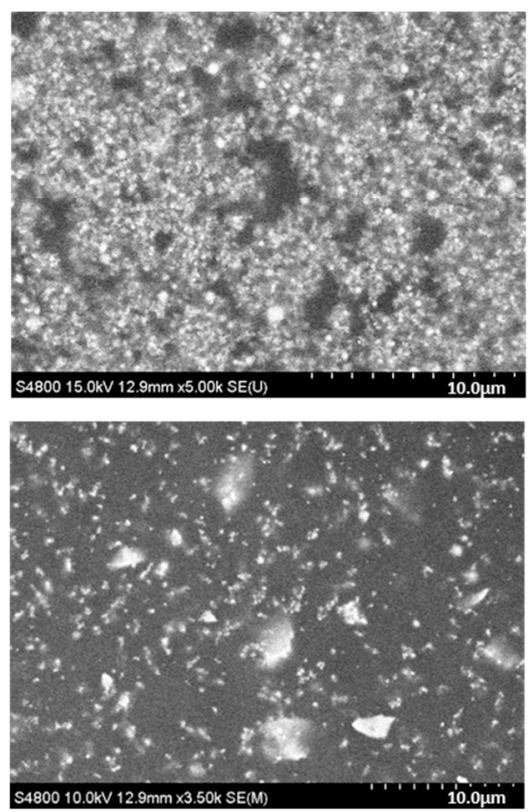

Figure 3. SEM images of the (a) PZT-, (b) SMA- and (c) PZT + SMA-particle-dispersed mixture films.

Figure 4 shows the measured loss factors of the specimens interleaved with PZTparticle-dispersed mixture films as functions of frequency. As stated earlier, the amount of dispersed PZT particles in the mixture film was varied from $0 \mathrm{~g} / \mathrm{m}^{2}$ to $25 \mathrm{~g} / \mathrm{m}^{2}$ with an increment of $5 \mathrm{~g} / \mathrm{m}^{2}$. The specimen denoted as "neat" was not interleaved with mixture films and served as a reference. As can be seen from Figure 4, in general, the measured loss factor increases with the particle loading. For the PZT interleaved specimens, the frequency range where the loss factor increases most is approximately between $100 \mathrm{~Hz}$ and $150 \mathrm{~Hz}$. The maximum loss factor peak was observed at $15 \mathrm{~g} / \mathrm{m}^{2}$ loading, and an improvement in loss factor can be observed up to $20 \mathrm{~g} / \mathrm{m}^{2}$ loading. In the case of $25 \mathrm{~g} / \mathrm{m}^{2}$, the loss factor shows almost no enhancement over neat specimens. It is presumed that, in the case of $25 \mathrm{~g} / \mathrm{m}^{2}$ loading film, the particle content was too high to make a film in which particles were uniformly dispersed. 


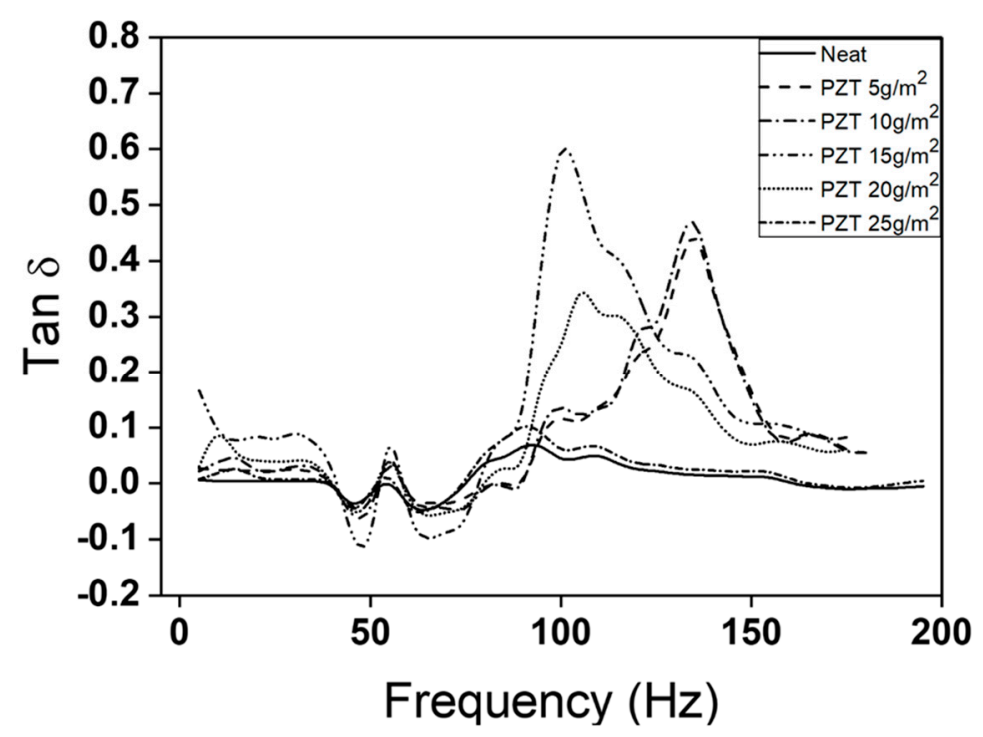

Figure 4. Loss factors of the CFRP specimens with PZT-particle-dispersed mixture films as functions of the frequency. Measurement data for different particle loadings.

Figure 5 shows the loss factors of the CFRP samples with PZT particles directly dispersed with between the composite plies at $120 \mathrm{~Hz}$ frequency. In previous research, a study was conducted through a specimen of composite materials in which PZT particles were directly dispersed. Existing results show that loss factor values are maximized at $120 \mathrm{~Hz}$ for specimens with direct distribution of PZT particles [25]. In this study, it was confirmed that the loss factor for different particle loadings was maximized in the range between $100 \mathrm{~Hz}$ and $150 \mathrm{~Hz}$ in a specimen using film-dispersed particles. However, in order to confirm the effect of particle dispersion on the loss factor through film dispersed particles, $120 \mathrm{~Hz}$, which can confirm the most maximized effect by directly spraying particles, was compared. In the case of film-interleaved specimens with particle contents of $5 \mathrm{~g} / \mathrm{m}^{2}$ to $20 \mathrm{~g} / \mathrm{m}^{2}$, the loss factor values are higher than those of directly dispersed specimens by up to two times or more. For the directly dispersed specimens, the improvement in the loss factors was observed up to the particle loading value of $15 \mathrm{~g} / \mathrm{m}^{2}$. For higher particle loadings, the loss factor decreased due to poor dispersion of particles. On the other hand, when the mixture film was used, an improvement in the loss factor could be observed up to $20 \mathrm{~g} / \mathrm{m}^{2}$. The method of using the mixture film rather than the direct application therefore can provide an improved damping capability through a better dispersion of particles. Kim et al. insisted that when using PZT particles dispersed by hand, it was revealed that the optimal content exists according to particle dispersion, and through this, the importance of particle dispersion was confirmed [8].

In order to confirm the improvement in particle dispersion by the use of the film, the cross-section of the specimen was further investigated using EPMA. Lead $(\mathrm{Pb})$ contained in the PZT particles was traced and mapped using the EPMA. As shown in Figure 6, good particle dispersion was confirmed. However, with the increase of the particle concentration, aggregations of the particles are formed, and the quality of dispersion deteriorates. Therefore, as described above, it is speculated that the cause of the decrease in loss factor for the particles loading at $25 \mathrm{~g} / \mathrm{m}^{2}$ is the deterioration in dispersion of particles in the film. SEM images of the cross-sections of the specimens are shown in Figure 7, which clearly shows aggregations and thus confirms that high particle concentration may be detrimental to the dispersion of particles. 


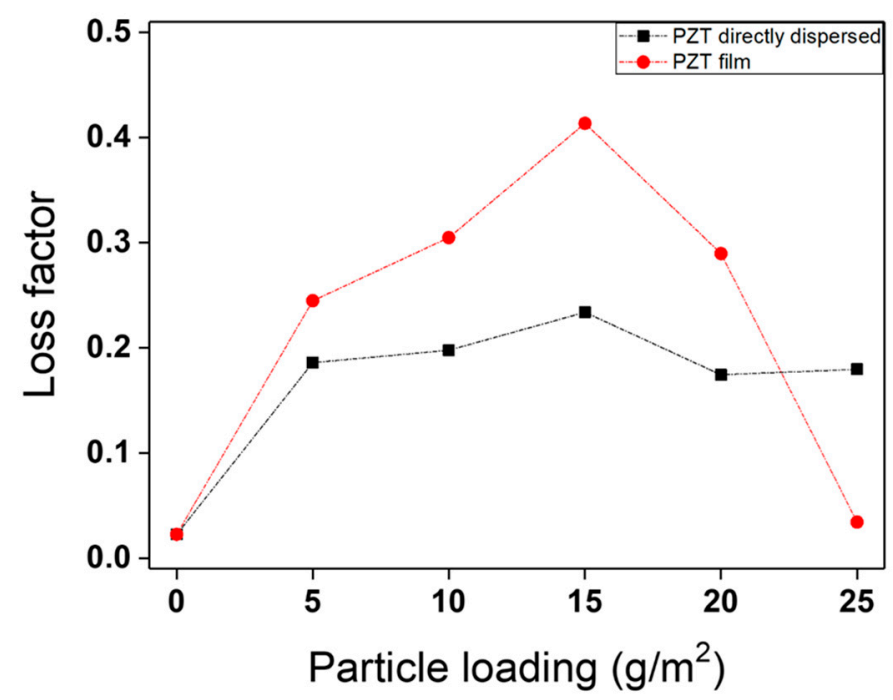

Figure 5. Loss factors of the specimens with PZT particle directly dispersed between the plies at $120 \mathrm{~Hz}$. Comparison with the specimens with mixture films. Measurement data for different particle loadings.
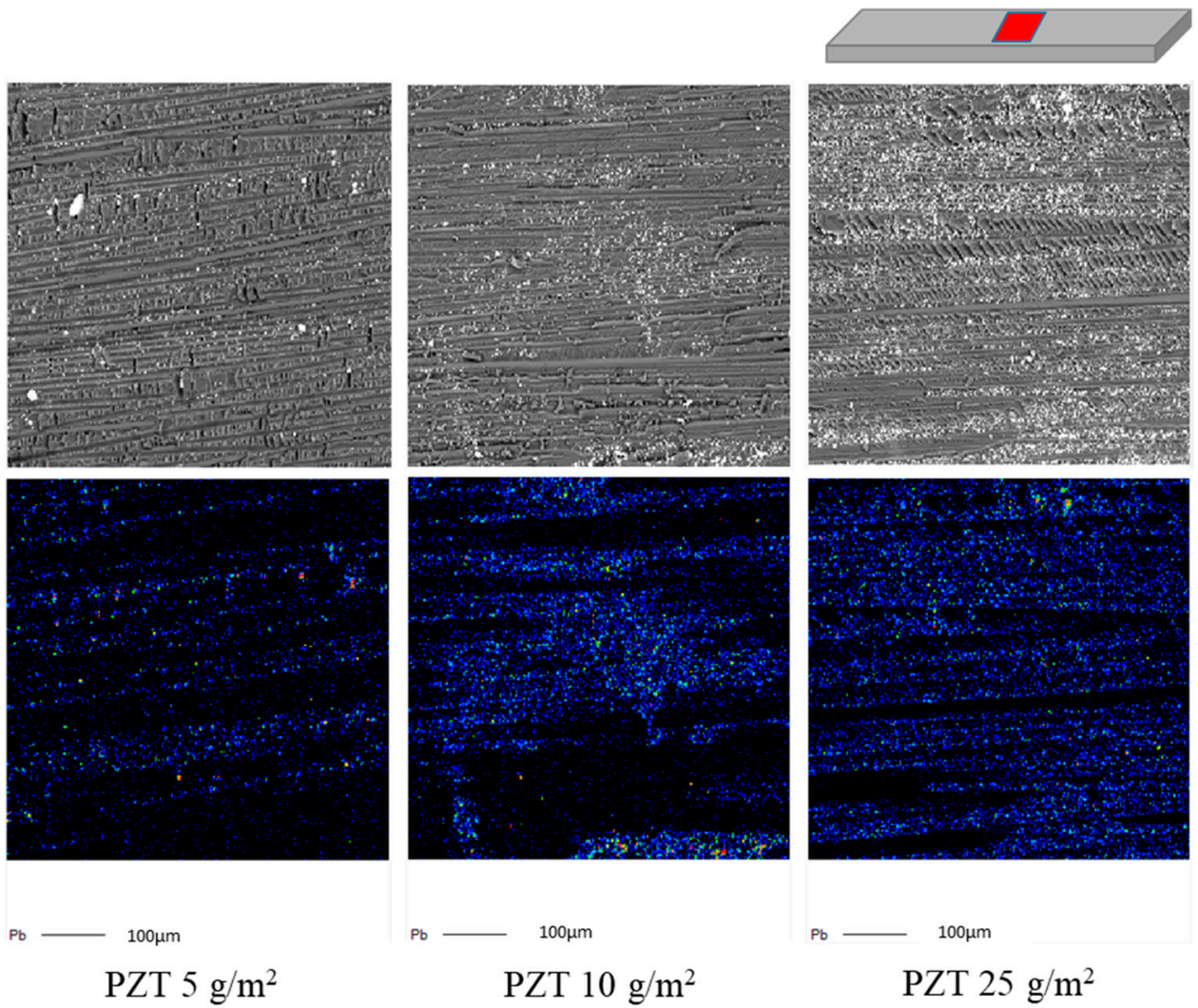

PZT $5 \mathrm{~g} / \mathrm{m}^{2}$

$$
\text { PZT } 10 \mathrm{~g} / \mathrm{m}^{2}
$$

PZT $25 \mathrm{~g} / \mathrm{m}^{2}$

Figure 6. EPMA mapping images of lead $(\mathrm{Pb})$ for evaluation of the dispersion of PZT in CFRP specimens. The blue dots show the degree of dispersion of the layer. The brighter the color, the stronger the signal from lead, which can be seen as large or clumped particles. 


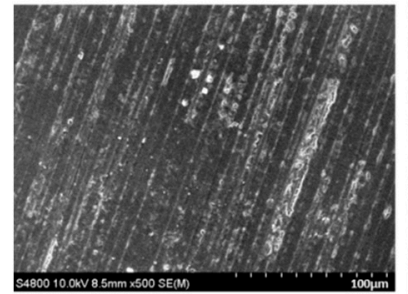

PZT $5 \mathrm{~g} / \mathrm{m}^{2}$

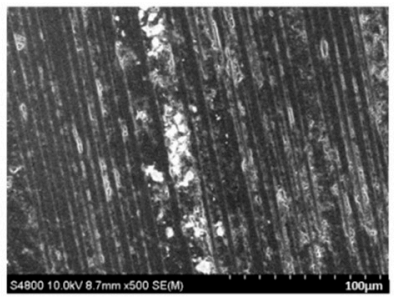

PZT $10 \mathrm{~g} / \mathrm{m}^{2}$

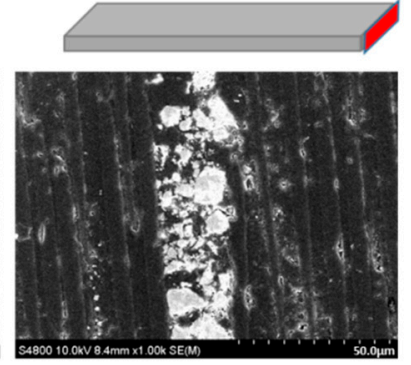

PZT $25 \mathrm{~g} / \mathrm{m}^{2}$

Figure 7. SEM images of fracture surfaces of the CFRP specimens with PZT specimens with different particle loadings.

Figure 8 shows the measured loss factors of the specimens interleaved with SMAparticle-dispersed mixture films as functions of frequency. Again, the amount of SMA particles in the mixture film varied from $0 \mathrm{~g} / \mathrm{m}^{2}$ to $25 \mathrm{~g} / \mathrm{m}^{2}$ with an increment of $5 \mathrm{~g} / \mathrm{m}^{2}$. As shown in Figure 8, the measured loss coefficient usually increases with the particle load. Unlike the PZT-particle-dispersed specimen, the loss factor value for the SMA-particledispersed specimen is higher than the neat specimen under all particle loading conditions. This difference is due to the different mechanisms of PZT and SMA on improving vibration damping within the composite material. In the case of PZT, dispersion inside the composite materials is very important because each electrical circuit should be connected through contact with carbon fiber to convert vibration energy into heat energy. In the case of SMA, the dispersion inside the composite material is less critical because it has vibration damping characteristics on its own due to its hyper-elastic property. In contrast to the specimens with PZT-particle-dispersed mixture films, for SMA interleaved specimens, the frequency range where the loss factor increases most were lower at approximately $50 \mathrm{~Hz}$ to $100 \mathrm{~Hz}$. A closer look at the results of Figure 8 shows that the highest loss factor value was measured in a specimen containing $20 \mathrm{~g} / \mathrm{m}^{2}$ particles overall.

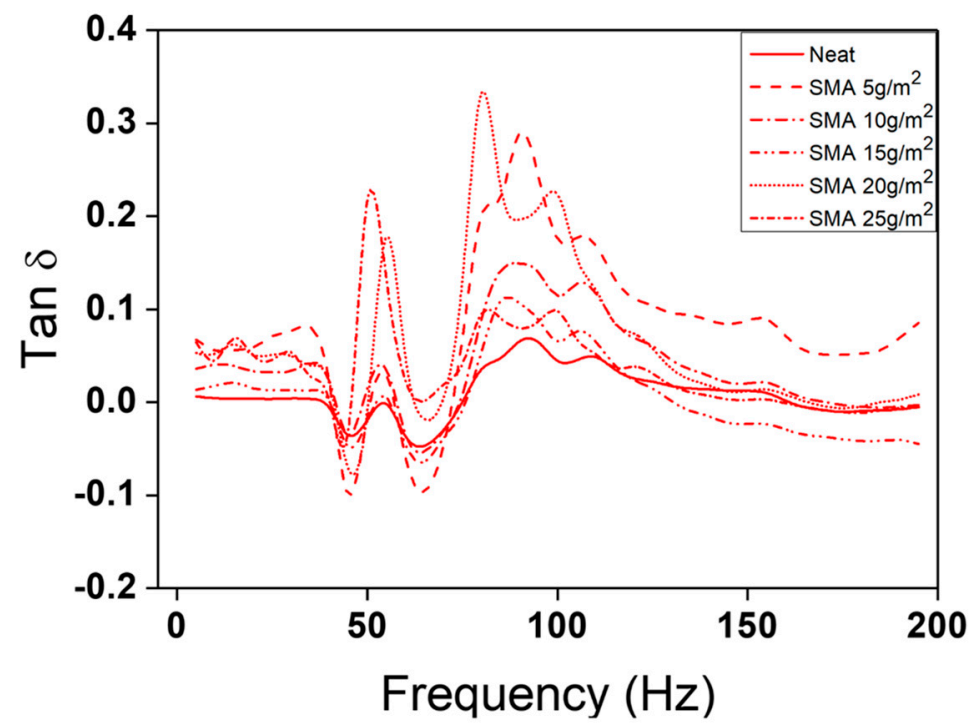

Figure 8. Loss factors $(\tan \delta$ ) of CFRP specimens with SMA-particle-dispersed mixture film as functions of the frequency. Measurement data for different particle loadings.

The DMA results of the carbon fiber composite material including mixed PZT and SMA-particle-dispersed mixture film (PZT + SMA) are shown in Figure 9. The partial content of each kind of particles in the mixture film is $10 \mathrm{~g} / \mathrm{m}^{2}$ each to make the total particle content of the film $20 \mathrm{~g} / \mathrm{m}^{2}$. In the figure, the loss factor values of PZT + SMA dispersed specimens are compared with those of PZT dispersed and SMA dispersed specimens. As 
mentioned above, the loss factor values of PZT + SMA dispersed specimens were measured to be larger than the loss factor of neat specimens in the whole frequency range.

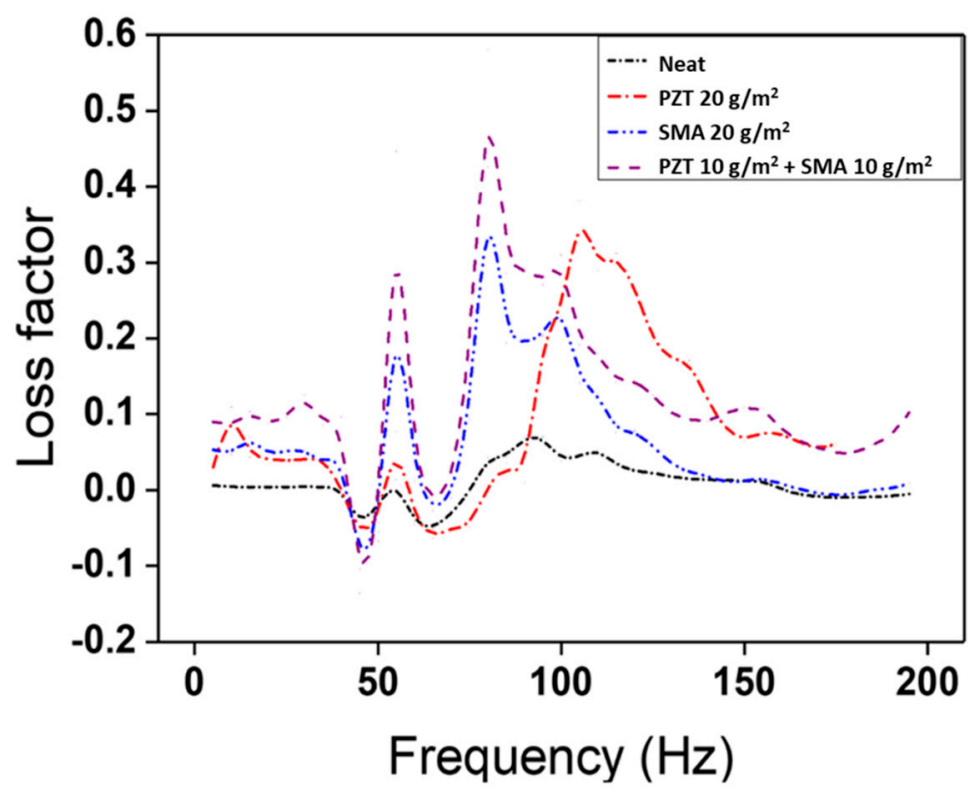

Figure 9. Loss factors $(\tan \delta$ ) of CFRP specimens with PZT, SMA and PZT/SMA mixed particledispersed mixture film. Measurement data for varying frequencies and different particle loadings.

It is interesting to note that the loss factor values of PZT + SMA dispersed specimens are higher than the specimens with SMA particles only in the whole frequency range. This is in contrast to the behavior of specimens with PZT particles; at 100-120 Hz, the PZT + SMA specimen had a lower loss factor value than the PZT particles specimen. Hartl et al. [26] showed that it is necessary for SMA to reach a temperature condition that can cause phase change inside the material in order to exhibit pseudoelasticity. It was also shown that the higher the temperature, the greater the energy consumed by deformation. Therefore, in SMA, the higher the temperature is, the faster the vibration energy can be dissipated. The thermal energy generated from the deformation of the PZT accelerates the phase change of the SMA when the piezoelectric material and the shape memory alloy are used simultaneously.

Another point that can be seen from the above experimental results is that the loss factor value is negative at a specific frequency. This is due to the resonance phenomenon of the specimen, as the frequency range with negative loss factor is almost similar for all specimens. According to Menard et al., as the specimen is scanned across its frequency range, the specimen-instrument system, such as a guitar string, begins to resonate when it reaches a certain frequency. These frequencies are either the natural resonant frequencies or harmonics of the sample-instrument system. In this set of experimental conditions, the sample-instrument system vibrates as a guitar string does, obscuring the desired information about the sample. Since this resonant behavior is a physical property of the system and there is no way to change it, the experiment must be redesigned by changing the sample dimensions or shape to avoid problems [27]. As mentioned above "Preparation of Specimens" section, all specimens used in this experiment have the same dimensions. Additionally, since the weight and elastic modulus are similar, it seems that resonance occurred at a similar frequency. The reason the negative value was measured can be seen as a calibration error of the measuring equipment or a calculation problem. However, before measuring the loss factor, the evaluation equipment should always be calibrated using a standard specimen before proceeding with the measurement. It seems that the direction of deflection of the specimen at the time of data measurement was measured as a negative number due to the resonance rather than the calibration of the measuring instrument, and the calculated value is considered to be negative. Normal values were output in the section 
over $100 \mathrm{~Hz}$ outside the resonance frequency, and since the section intensively analyzed for material properties in this study is the section over $100 \mathrm{~Hz}$, it is not expected to have a significant impact on the validity of the experimental results.

Figure 10 shows the flexural modulus of the CFRP samples interleaved with PZT-, SMA-, and mixed-particle-dispersed mixture films. The measured values showed no significant change as the content of the particles increases regardless of the type of material. This indicates that the interleaved mixture film does not act as a defect that degrades the mechanical properties of the material. It is safe to say, therefore, that interleaving PZT, SMA, and PZT + SMA particles mixture films in composite laminates can improve vibration damping capability without deteriorating the mechanical properties of the material.

(a)

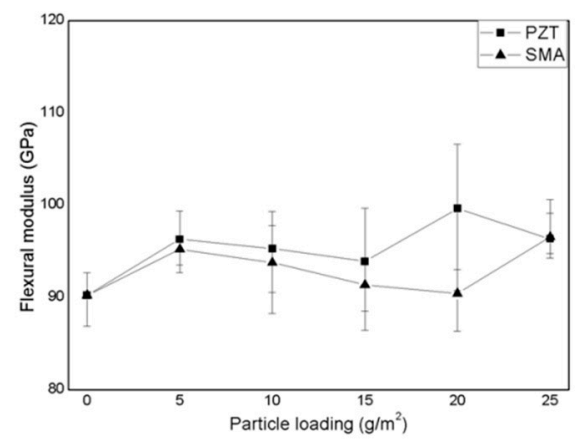

(b)

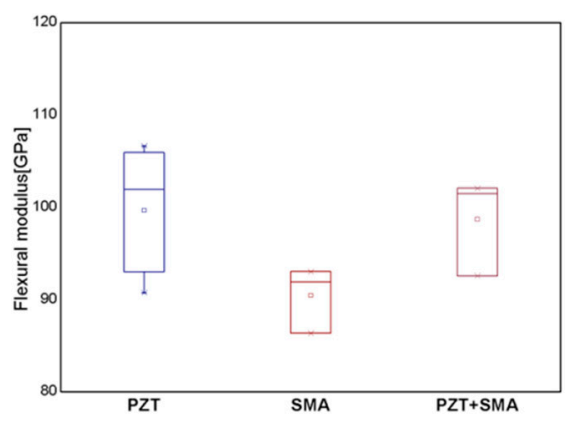

Figure 10. Flexural modulus of the CFRP specimens with (a) PZT- and SMA-particle-dispersed mixture films for different particle loadings and (b) PZT-, SMA-, and PZT $10 \mathrm{~g} / \mathrm{m}^{2}$ loading/SMA $10 \mathrm{~g} / \mathrm{m}^{2}$ loading mixed-particle-dispersed mixture films.

\section{Conclusions}

In this study, functional particles such as piezoelectric (PZT) ceramic and shape memory alloy (SMA) particles have been incorporated in composite laminates to accelerate the loss of vibration energy. PZT ceramic particles and SMA particles are mixed with epoxy resin and rolled into a film shape before they are interleaved between prepreg plies for better distribution of the particles. In this study, $20 \mu \mathrm{m}$ thickness epoxy resins film with well-dispersed particles was produced to improve particle dispersion inside composite materials. The loss factor $(\tan \delta)$ was measured with various particle loadings to verify the effectiveness of interleaving in the vibration damping of laminate specimens. Therefore, dispersed particles used in this study increased the vibration damping capacity without reducing the mechanical properties.

Through SEM and EPMA, the degree of dispersion of particles inside the composite material was evaluated, and it was observed that the particles were well distributed between the composite interplies. However, in the case of the $25 \mathrm{~g} / \mathrm{m}^{2}$ specimen, PZT particles were found to form aggregates between the composite interplies. This confirmed that applying more than $25 \mathrm{~g} / \mathrm{m}^{2}$ of particles to a thin mixture film of $20 \mu \mathrm{m}$ thickness would lead to a decrease in dispersion.

Mixture films were produced, where the content of PZT and SMA particles varied from $0 \mathrm{~g} / \mathrm{m}^{2}$ to $25 \mathrm{~g} / \mathrm{m}^{2}$ in an increment of $5 \mathrm{~g} / \mathrm{m}^{2}$, to verify the vibration damping performance according to the content of the particles. To evaluate the vibration damping of the manufactured composite specimens, the loss factor was measured using DMA. It was recognized that there was an optimal particle content to improve vibration damping performance.

In order to verify the vibration damping effect when PZT and SMA particles are applied at the same time, a film containing $10 \mathrm{~g} / \mathrm{m}^{2}$ particles content of each material was produced. In this case, the loss factor was improved in all frequency ranges. In addition, when PZT and SMA are applied simultaneously, PZT is expected to enhance the vibration damping performance of SMA.

The flexural modulus was measured to confirm whether the introduction of interleaves between composite plies affects the mechanical properties of the material. Little change 
in flexural modulus with the content of the particles was observed. Therefore, dispersed particles used in this study increased the vibration damping capacity without reducing the mechanical properties.

This study demonstrates an effective way to improve the vibration damping of synthetic laminates through interleaving of particle/resin mixed films. We propose optimal conditions to improve the vibration damping capability of the composite by attempting various particles and particle loads.

Author Contributions: Conceptualization, J.-M.J. and W.-I.L.; validation, J.-M.J., D.-S.L., S.-N.M. and W.-I.L.; formal analysis, J.-M.J. and D.-S.L.; investigation, J.-M.J. and S.-H.K.; resources, S.-M.K.; data curation, J.-M.J. and D.-S.L.; writing-original draft preparation, J.-M.J.; writing-review and editing, J.-M.J.; visualization, D.-S.L.; supervision, S.-M.K.; project administration, W.-I.L.; funding acquisition, S.-M.K. All authors have read and agreed to the published version of the manuscript.

Funding: This work was supported by the research program (NRF-2020M3D1A2102467) funded by National Research Foundation of Korea.

Institutional Review Board Statement: Not applicable.

Informed Consent Statement: Not applicable.

Data Availability Statement: Not applicable.

Conflicts of Interest: The authors declare no conflict of interest.

\section{References}

1. Nielsen, L.E.; Landel, R.F. Mechanical Properties of Polymers and Composites; CRC Press: Boca Raton, FL, USA, 1994.

2. Song, G.; Qiao, P.; Binienda, W.; Zou, G. Active vibration damping of composite beam using smart sensors and actuators. J. Aerosp. Eng. 2002, 15, 97-103. [CrossRef]

3. Rao, M.D.; Echempati, R.; Nadella, S. Dynamic analysis and damping of composite structures embedded with viscoelastic layers. Compos. Part B Eng. 1997, 28, 547-554. [CrossRef]

4. Zhou, X.; Shin, E.; Wang, K.W.; Bakis, C.E. Interfacial damping characteristics of carbon nanotube-based composites. Compos. Sci. Technol. 2004, 64, 2425-2437. [CrossRef]

5. Treviso, A.; Van Genechten, B.; Mundo, D.; Tournour, M. Damping in composite materials: Properties and models. Compos. Part B Eng. 2015, 78, 144-152. [CrossRef]

6. Uchino, K. Ferroelectric Devices; CRC Press: Boca Raton, FL, USA, 2018.

7. Hori, M.; Aoki, T.; Ohira, Y.; Yano, S. New type of mechanical damping composites composed of piezoelectric ceramics, carbon black and epoxy resin. Compos. Part A Appl. Sci. Manuf. 2001, 32, 287-290. [CrossRef]

8. Kim, S.Y.; Tanimoto, T.; Uchino, K.; Nam, C.H.; Nam, S.; Lee, W.I. Effects of PZT particle-enhanced ply interfaces on the vibration damping behavior of CFRP composites. Compos. Part A Appl. Sci. Manuf. 2011, 42, 1477-1482. [CrossRef]

9. Tanimoto, T. A new vibration damping CFRP material with interlayers of dispersed piezoelectric ceramic particles. Compos. Sci. Technol. 2007, 67, 213-221. [CrossRef]

10. Uchino, K. Mechanical Damper using Piezoelectric Ceramics. J. Jpn. Ceram. Soc. 1988, 96, 863. [CrossRef]

11. Yazdani, A.; Manesh, H.D.; Zebarjad, S.M. Piezoelectric properties and damping behavior of highly loaded PZT/polyurethane particulate composites. Ceram. Int. 2021. [CrossRef]

12. Lagoudas, D.C. Shape Memory Alloys: Modeling and Engineering Applications; Springer: Berlin/Heidelberg, Germany, 2008.

13. Jacson, C. 55-Nitinol-the alloy with a memory: Its physical metallurgy, properties and applications. NASA-SP-5110 1972, 15, 59-68.

14. Duerig, T.W.; Melton, K.; Stöckel, D. Engineering Aspects of Shape Memory Alloys; Elsevier: Amsterdam, The Netherlands, 2013.

15. Otsuka, K.; Wayman, C.M. Shape Memory Materials; Cambridge University Press: Cambridge, UK, 1999.

16. Perez-Saez, R.; Recarte, V.; Nó, M.; San Juan, J. Anelastic contributions and transformed volume fraction during thermoelastic martensitic transformations. Phys. Rev. B 1998, 57, 5684. [CrossRef]

17. Van Humbeeck, J. Damping capacity of thermoelastic martensite in shape memory alloys. J. Alloy. Compd. 2003, 355, 58-64. [CrossRef]

18. De Araújo, C.; Rodrigues, L.; Neto, J.C.; Reis, R. Fabrication and static characterization of carbon-fiber-reinforced polymers with embedded NiTi shape memory wire actuators. Smart Mater. Struct. 2008, 17, 065004. [CrossRef]

19. Piedboeuf, M.; Gauvin, R.; Thomas, M. Damping behaviour of shape memory alloys: Strain amplitude, frequency and temperature effects. J. Sound Vib. 1998, 214, 885-901. [CrossRef]

20. San Juan, J.; Nó, M.L.; Schuh, C.A. Nanoscale shape-memory alloys for ultrahigh mechanical damping. Nat. Nanotechnol. 2009, 4, 415-419. [CrossRef] [PubMed] 
21. Quiroga, L.; SANCHES, L.; Bessaguet, C.; Chevalier, M.; Lacabanne, C.; Dantras, E.; Michon, G. Improving damping capabilities of composites structures by electroactive films containing piezoelectric and conductive fillers. Smart Mater. Struct. 2021. [CrossRef]

22. Dong, Z.J.; Liu, Q.S.; Lv, L.R.; Gao, X.Y.; Kong, D.Q. Microstructure and Damping Property of the Discontinuous NiTi SMA Thin Films /PZT Substrate Composite. In Advanced Materials Research; Trans Tech Publications Ltd.: Freienbach, Switzerland, 2012; pp. 427-434.

23. ASTM D5023-07. Standard Test Method for Plastics: Dynamic Mechanical Properties: In Flexure (Three-Point Bending); ASTM International: West Conshohocken, PA, USA, 2007. [CrossRef]

24. ASTM D790-17. Standard Test Methods for Flexural Properties of Unreinforced and Reinforced Plastics and Electrical Insulating Materials; ASTM International: West Conshohoken, PA, USA, 2017. [CrossRef]

25. Jung, J.; Lee, W.I.; Lee, D.; Park, S.; Moon, S. Passive vibration damping of carbon fiber reinforced plastic with PZT particles and SMA powder. In Active and Passive Smart Structures and Integrated Systems 2016; International Society for Optics and Photonics: Bellingham, WA, USA, 2016; p. 97990Y.

26. Hartl, D.; Lagoudas, D. Thermomechanical characterization of shape memory alloy materials. In Shape Memory Alloys; Springer: Berlin/Heidelberg, Germany, 2008; pp. 53-119.

27. Menard, K.P.; Menard, N.R. Dynamic mechanical analysis in the analysis of polymers and rubbers. Encycl. Polym. Sci. Technol. 2002, 1-33. [CrossRef] 